\title{
DEVELOPMENT OF A THIN FILM 9.17 MeV GAMMA RAY PRODUCTION TARGET FOR THE CONTRABAND DETECTION SYSTEM
}

\author{
S. T. Melnychuk, AES Inc., Medford, NY; R. Meilunas, Northrop Grumman Corp., Bethpage, NY.
}

\begin{abstract}
We will describe the development of a thin film ${ }^{13} \mathrm{C}$ target for generating $9.17 \mathrm{MeV}$ gamma rays via a $(\mathrm{p}, \gamma)$ reaction for use in a commercial Contraband Detection System (CDS) employing Nuclear Resonance Absorption. The target required for this system must consist of a thin ${ }^{13} \mathrm{C}$ film backed by a high $\mathrm{Z}$ proton stopping layer. It must be able to withstand average proton beam powers of 17.5 $\mathrm{kW}$, implanted ion doses greater than $10^{19} / \mathrm{cm}^{2}$ and peak power densities approaching $50 \mathrm{~kW} / \mathrm{cm} 2$ for extended periods of time. These requirements currently cannot be met by conventional target designs employing $\mathrm{C} / \mathrm{Au}$ structures. After even short exposure times of several minutes to the proton beam the targets suffer from coating de-lamination and blistering. A new more durable target design has been developed which suffers no such degradation after many hours of beam exposure. The new design consists of a thin ${ }^{13} \mathrm{C}$ film deposited onto a Ta layer which has been brazed onto a $\mathrm{Cu}$ cooling support.
\end{abstract}

\section{INTRODUCTION}

The design of the CDS accelerator has been described previously [1], and operating characteristics of the machine are given in $[2,3]$. For full power operation a $10 \mathrm{~mA}, 1.76 \mathrm{MeV}$ circular spot beam is required with an rms radius of approximately $2.5 \mathrm{~mm}$. For a Gaussian beam at $95 \%$ beam fraction this gives an average power density of $16 \mathrm{~kW} / \mathrm{cm}^{2}$ with peak densities at the center of the spot about $3-4$ times greater.

In order to effectively cool the target a rotating water cooled disk design was chosen. The thermomechanical design is described in detail in [4]. The work described in this paper focussed on the thin film target design, testing and fabrications, and on the issues specific to radiation damage associated with high proton doses.

The generic structure of the gamma production target consists of a thin film of ${ }^{13} \mathrm{C}(1-2 \mu \mathrm{m})$ deposited onto a high $\mathrm{Z}$ proton stopping material attached to a water cooled substrate. At $1.76 \mathrm{MeV}$ the range of beam in most suitable stoppers is $12-14 \mu \mathrm{m}$ with a straggle of about $2.5 \mu \mathrm{m}$. In order not to generate any gamma rays that may interfere with the desired signal the proton beam is required to stop completely in the high $\mathrm{Z}$ layer.

Due to programmatic constraints target development and testing had to be initiated prior to the availability of the CW CDS accelerator. This was done using the AES $1.76 \mathrm{MeV}$ pulsed linac capable of providing $20 \mathrm{~mA}$ at $700 \mu \mathrm{s}$ and $10 \mathrm{~Hz}$, and the Northrop Grumman VandeGraff accelerator.
Figure 1 shows the various configurations that were tested. Initially all target testing was done using 5 $\mathrm{cm}$ diameter coupons coated with ${ }^{12} \mathrm{C}$ on various stopping layers and substrates.

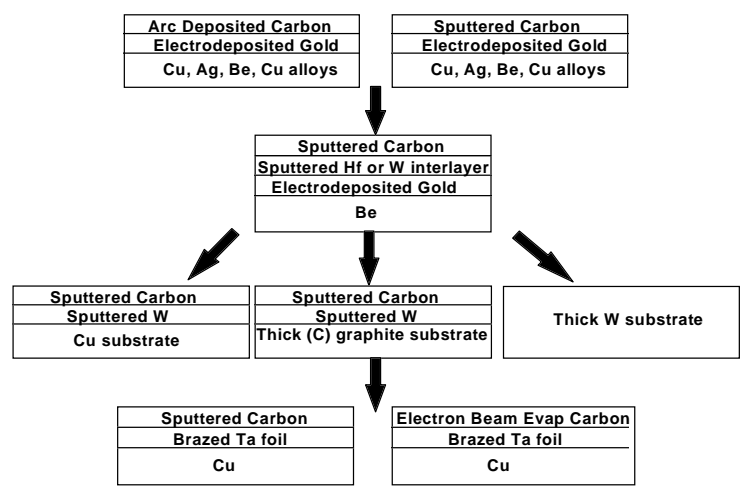

Figure 1. Target configurations we have tested.

The experimental program addressed the issues of: fabrication of ${ }^{12} \mathrm{C}$ test coupons by techniques extendable to ultimate fabrication of a ${ }^{13} \mathrm{C} \mathrm{CW}$ target, measurements of target temperature rise during the beam pulse, effects of implanted hydrogen dose, measurements of gamma ray production.

\section{EXPERIMENTAL RESULTS}

Test coupons were mounted in a water cooled holder and exposed to the pulsed beam from the RF linac. The expected temperature rise of the target surface based on the solution of the $1 \mathrm{~d}$ heat equation for a pulsed heat input is given by: $\Delta \mathrm{T}=2 \mathrm{~W} V(\mathrm{t} /(\pi \rho \mathrm{ck}))$, where $\rho$ is the density, $\mathrm{c}$ the specific heat, $\mathrm{k}$ the thermal conductivity, and $\mathrm{W}$ the power density.

Measurements of surface temperature rise during beam bombardment were performed using a specially designed radiometer with a $0.5 \mathrm{~mm}$ spatial resolution and a $1 \mu \mathrm{s}$ time response. These measurements confirmed that the surface temperature rise was reasonably given by the expression above provided that the $\mathrm{C}$ thin film did not delaminate. If target blistering occurred then significantly higher temperatures were observed in localised areas where blisters were forming.

Typical measured temperature rises during the beam pulse were $300 \mathrm{~K}$ to $400 \mathrm{~K}$ depending on pulse length and power density used. Fig. 2 shows the results of scans along the major and minor axes of an elliptical beam on a sputtered ${ }^{12} \mathrm{C} / \mathrm{Hf} / \mathrm{Au} / \mathrm{Be}$ target. The solid curves show the calculated response. 


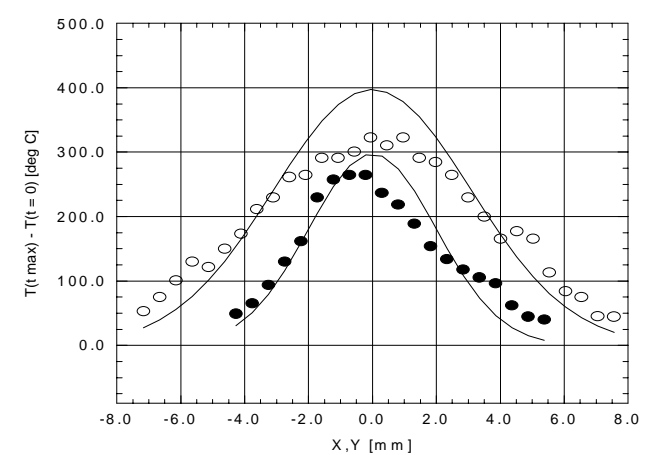

Fig. 2. Temperature profile of ${ }^{12} \mathrm{C} / \mathrm{Hf} / \mathrm{Au} / \mathrm{Be}$. (O) Vertical. I: $10.4 \mathrm{~mA}$, Pulse: $440 \mu \mathrm{s}, \mathrm{y}(\mathrm{rms}): 3.1 \mathrm{~mm}$; $(\bullet)$ Horiz.. I: 7.4 mA, Pulse: $400 \mu \mathrm{s}, \mathrm{x}(\mathrm{rms}): 1.9 \mathrm{~mm}$.

$\mathrm{Au}$ electrodeposited on a variety of substrates showed deterioration of both the carbon and Au layers. The deterioration of the Au based targets was in the form of blister formation and delamination of both the $\mathrm{C}$ and $\mathrm{Au}$ layers from their underlying substrates. Fig. 3a shows arc deposited $\mathrm{C}$ on $10 \mu \mathrm{m}$ of electrodeposited $\mathrm{Au}$ on $\mathrm{Be}$ after a 12 hour beam exposure at $10 \mathrm{~mA}, 500 \mu$ s pulse, and $10 \mathrm{~Hz}$ rep rate. Delamination of the $\mathrm{C}$ is evident. Fig. $3 b$ shows the development of blisters on a $\mathrm{C} / \mathrm{Au} / \mathrm{Cu}$ target where the blister density increases at the beam edge with relatively little blistering at the beam center, and the blister size increases toward the beam center. The development of this type of feature caused us to initially question the beam profile, however target temperature profiles as shown above, and independent beam profiles obtained with an emittance scanner confirmed that the beam was gaussian.

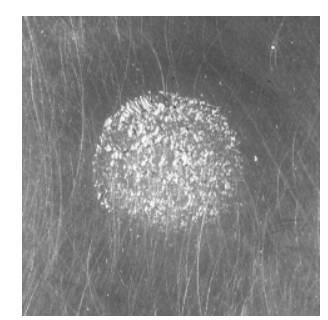

(a)

Fig. 3: (a) Sputtered ${ }^{12} \mathrm{C}$ on $10 \mu \mathrm{m}$ Au electrodeposited on $\mathrm{Ni}$ flashed Be. Avg. dose: 1.2e19ions $/ \mathrm{cm}^{2}$. (b) Arc deposited ${ }^{12} \mathrm{C}$ on $10 \mu \mathrm{m}$ Au electrodeposited on $\mathrm{Cu}$.

This phenomenon of preferential blistering at the beam edge was observed on several of our samples, and similar effects have been observed in $\mathrm{Cu}$ implanted with $30 \mathrm{MeV} \alpha$-particles in ref. [5 - p.291]. This has been explained as being due to the trapping of vacancies arriving from outside the implant range at the borders of the gas rich area.

To test if the observed blistering may not have been due to trapping of $\mathrm{H}$ at the $\mathrm{Au} / \mathrm{Be}$ or $\mathrm{Au} / \mathrm{Cu}$ interface due to a film thickness comparable to the implant range, tests were conducted with $20 \mu \mathrm{m}$ and $40 \mu \mathrm{m}$ of $\mathrm{Au}$ electrodeposited on Be. These tests also showed blistering of the Au at average doses of $8 \mathrm{E} 18$ ions $/ \mathrm{cm}^{2}$, suggesting that this was a fundamental property of the $\mathrm{Au} / \mathrm{H}$ system.

Based on the performance of the Au targets we began to investigate materials which were carbide formers in order to improve the adhesion of the $\mathrm{C}$ films to the high $\mathrm{Z}$ layer. Coupons were fabricated by magnetron sputtering $50 \mathrm{~nm}$ of W or Hf onto $20 \mu \mathrm{m}$ of $\mathrm{Au}$ on Be followed by $1 \mu \mathrm{m}$ of sputtered C. Exposure of the $\mathrm{C} / \mathrm{Hf} / \mathrm{Au} / \mathrm{Be}$ target to the beam at a dose of $9 \mathrm{E} 18 \mathrm{ion} / \mathrm{cm}^{2}$ showed only very minor blistering with no $\mathrm{C}$ delamination. Fig. 4a shows the $\mathrm{C} / \mathrm{Hf} / \mathrm{Au} / \mathrm{Be}$ target after beam exposure. Some "wrinkling" of the surface is evident. Exposure of the $\mathrm{W}$ interlayer target to a comparable dose showed the development of small blisters at the beam edge similar to those observed in fig. $3 \mathrm{~b}$, however no $\mathrm{C}$ delamination was evident. (a)

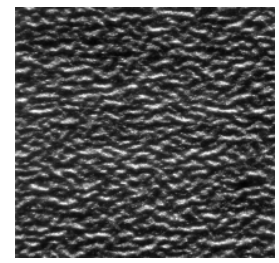

(b)

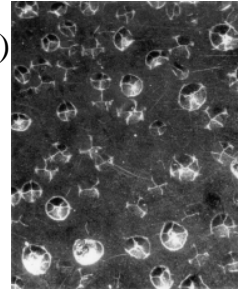

Fig. 4. Targets after beam exposure. (a) C/50 nm $\mathrm{Hf} / \mathrm{Au} / \mathrm{Be}$. (b) Thick W plate.

The difference between the Hf/Au and W/Au systems is in the hydrogen solubility. Metals such as $\mathrm{Mg}$, $\mathrm{Al}, \mathrm{Si}, \mathrm{Cr}, \mathrm{Mn}, \mathrm{Fe}, \mathrm{Co}, \mathrm{Cu}, \mathrm{Mo}, \mathrm{Ag}, \mathrm{W}, \mathrm{Pt}$, and $\mathrm{Au}$ form simple solutions, do not form hydrides and are endothermic with respect to hydrogen solubility. When samples of these metals loaded with hydrogen at high temperature are quenched they tend to precipitate hydrogen in the form of bubbles.

Metals such as $\mathrm{Ti}, \mathrm{Zr}, \mathrm{V}, \mathrm{Nb}, \mathrm{Ta}$, and $\mathrm{Hf}$ form more than one phase when the simple solution is saturated, can accommodate relatively high hydrogen concentrations, are strongly exothermic, and can accommodate approximately $1 \mathrm{H}$ atom per metal atom [5].

Irradiation either of $\mathrm{W}$ plate or $\mathrm{W}$ sputtered films all showed significant deterioration after a dose of $5 \mathrm{e} 18$ ions $/ \mathrm{cm}^{2}$. Fig. $4 \mathrm{~b}$ shows an irradiated $\mathrm{W}$ plate with the blister size varying from approximately $200 \mu \mathrm{m}$ at the spot center to $<50 \mu \mathrm{m}$ at the beam edge, and an increase in blister density at the beam edge.

These results led to the abandonment of $\mathrm{Au}$ based targets in favor of $0.127 \mathrm{~mm}$ thick Ta foils vacuum brazed onto $\mathrm{Cu}$. These foils showed no visible degradation after 12 hours of beam exposure and an average dose of $10^{19}$ ions $/ \mathrm{cm} 2$ with a $3-5$ times greater peak dose. 
The brazed $\mathrm{Ta}$ on $\mathrm{Cu}$ structure has become our baseline for the first CDS targets.
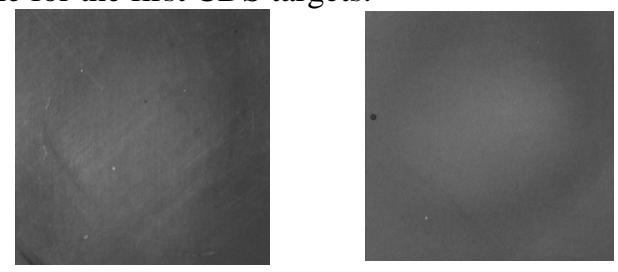

Fig. 5. (a) Sputtered C on brazed Ta foil. (b) ebeam evaporated $\mathrm{C}$ on brazed Ta foil. Dose: 1e19 ion $/ \mathrm{cm}^{2}$.

Two deposition techniques for ${ }^{13} \mathrm{C}$ were used : magnetron sputtering; and electron beam evaporation. The advantage of sputtering is that we get good film adhesion, relatively low substrate temperatures are required $(<300 \mathrm{C})$, we have the ability to coat large areas by rotating the target, and the deposition rate is fairly uniform. The disadvantages are the relatively high cost of the ${ }^{13} \mathrm{C}$ sputter target and poor sputter target utilization. This technique was used to coat the rotating high power target described in [4]. Electron beam evaporation has the advantage of maintaining a low substrate temperature, and the ability to coat large areas. The disadvantages of the process are a non-uniform deposition rate due to the sublimation of ${ }^{13} \mathrm{C}$ from pressed powder pellets, poorer adhesion than from sputtering, and more labor required due to less process automation.

Brazed $\mathrm{Ta}$ on $\mathrm{Cu}$ targets were coated with ${ }^{12} \mathrm{C}$ using both of these techniques. These targets shown in fig. 5, were tested for survivability at a dose of $10^{19}$ ions $/ \mathrm{cm} 2$ with no degradation of the films.

Experiments were conducted on the VandeGraff accelerator to examine the gamma ray spectra of the sputtered and electron beam evaporated targets. Early targets produced in the sputter chamber showed evidence of fluorine contamination and characteristics fluorine lines were seen in the gamma spectra in the region of 5 to $7 \mathrm{MeV}$. This contamination was found to result from the use of fluoridated pump oil in the roughing pump.

After switching to a non-fluoridated oil and cleaning the chamber the fluorine spectral features disappeared from the sputtered targets. Fig. 6a shows spectra for an evaporated clean ${ }^{13} \mathrm{C}$ target, and a contaminated ${ }^{12} \mathrm{C}$ target. In the ${ }^{13} \mathrm{C}$ target we can see the 9.17 MeV gamma ray grouping with the first and second escape peaks.

A target thickness measurement was performed using the VandeGraff on the ${ }^{13} \mathrm{C}$ target by measuring the gamma ray yield as a function of proton beam energy. This showed an energy width of $4 \mathrm{keV}$ implying at the target thickness was approx. $0.25 \mu \mathrm{m}$. We have utilized this measurement to calibrate our electron beam evaporation rate and have since produced $1.0 \mu \mathrm{m}, 1.5 \mu \mathrm{m}$ and $2.0 \mu \mathrm{m}$ thick evaporated targets. Fig. $6 \mathrm{~b}$ shows the thin target response from the VandeGraff measurements and a target response obtained on the CW CDS accelerator showing that the target was thick enough to generate $9.17 \mathrm{MeV}$ gammas across the entire CDS beam

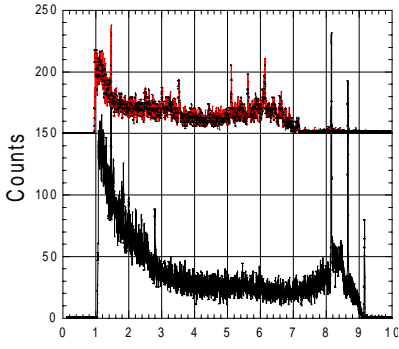

Gamma Energy [MeV]

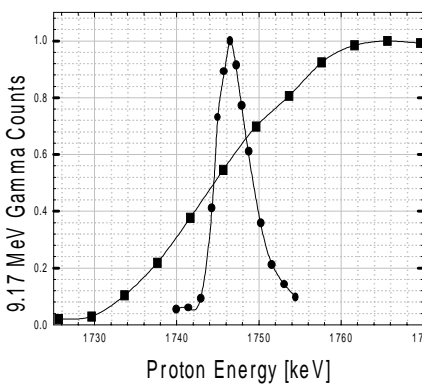

energy spread.

Fig. 6. (Left) Gamma spectrum showing F contaminated spectrum (upper) and clean spectrum (lower) with the $9.17 \mathrm{MeV}$ grouping. (Right) $9.17 \mathrm{MeV}$ gamma ray yield curve measured on CDS accelerator ( $\mathbf{\square})$, and from the VandeGraff $(\bullet)$.

\section{CONCLUSION}

We have found a baseline target configuration utilizing either magnetron sputtered or evaporated ${ }^{13} \mathrm{C}$ deposited on $\mathrm{Ta}$ foil brazed onto $\mathrm{Cu}$. This configuration is able to withstand high hydrogen doses without deterioration of either the $\mathrm{C}$ or the Ta stopping layer because of a high hydrogen diffusivity and solubility in $\mathrm{Ta}$, and the ability of Ta to form carbides and bind with the $\mathrm{C}$ thin film. This configuration has been operated under pulsed and CW beam conditions at average doses of $10^{19}$ ions $/ \mathrm{cm} 2$ with no deterioration. For a clean gamma spectrum fluorine containing pump oils must be avoided. Gamma yield measurements on the CDS accelerator show that the target was thick enough to use the full proton energy spread.

\section{REFERENCES}

1. J.J. Sredniawski, et.al. , Proc. of 18th Int. Lin. Accel. Conf., vol. 1, 26-30 Aug. 1996, p. 444.

2. S. T. Melnychuk, et. al., Proc. of 18th Int. Lin. Accel. Conf., vol. 2, 26-30 Aug. 1996, p. 479.

3. S. T. Melnychuk et. al., "Operating Characteristics of a High Current Electrostatic Accelerator for a Contraband Detection System", This Conference.

4. J. Rathke, This Conference.

5. B. Scherzer in "Sputtering by Particle Bombardment II" ed. By: R. Behrisch, Springer Verlag, NY,ISBN3-540-12593-0 p. 271. 